\title{
Risk Factors of Pulmonary Complications After Minimally Invasive Surgery for Elderly Patients with Vertebral Compression Fractures
}

This article was published in the following Dove Press journal:

Therapeutics and Clinical Risk Management

\author{
Hua-Xing Zhang ${ }^{1,2}$ \\ Yong Shen (iD) \\ Jia Chen ${ }^{2}$ \\ Long Zhang ${ }^{2}$ \\ Wei Lin'
}

'Department of Graduate School, Graduate School of Hebei Medical University, Shijiazhuang, Hebei 050000, People's Republic of China; ${ }^{2}$ Department of Orthopedics, Hebei General Hospital, Shijiazhuang, Hebei 050000, People's Republic of China; ${ }^{3}$ Department of Spine Surgery, The Third Affiliated Hospital of Hebei Medical University, Shijiazhuang, Hebei 050000, People's Republic of China
Correspondence: Yong Shen

Department of Spine Surgery, The Third Affiliated Hospital of Hebei Medical University, No. 139, Ziqiang Road, Xinhua District, Shijiazhuang, Hebei, Province 050000, People's Republic of China

Tel +86- $|8533| \mid 2820$

Fax +86-03।I-85988832

Email shenyonghbgh2018@I26.com
Purpose: To determine the risk factors for pulmonary complications after minimally invasive surgery in elderly patients with vertebral compression fractures (VCFs).

Methods: A total of 233 elderly patients (age $\geq 65$ years) with VCFs, who underwent percutaneous vertebroplasty (PVP) or percutaneous kyphoplasty (PKP) surgery at Hebei General Hospital from January 2011 to December 2016, were retrospectively analyzed. Risk factors and the effects of the model were determined by univariate logistic regression analyses and the receiver operating characteristic (ROC) curve, respectively. A risk assessment scale was established based on the risk factors, as well as physiological and surgical scores for mortality and morbidity. The risk assessment scale prospectively evaluated risk factors of pulmonary complications after minimally invasive surgery for elderly patients with VCFs from January to June 2017.

Results: 27 patients were diagnosed with pulmonary complications $(27 / 233,11.59 \%)$. There were statistically significant differences between patients with and without pulmonary complications in terms of age, body mass index (BMI), smoking, cardiovascular diseases and old fractures between patients with and without pulmonary complications $(\mathrm{P}<0.05)$. Logistic regression analysis showed that smoking, cardiovascular diseases and old fractures were risk factors $(\mathrm{P}<0.05)$ and area under the curve was $0.738(95 \%$ confidence intervals (CI): 0.648-0.828). 53 elderly patients with VCFs were assessed, 5 of them occurred pulmonary complications. Areas under the curve of preoperative and total risk assessment values were all 0.925 .

Conclusion: Significant risk factors of pulmonary complications were BMI, cardiovascular diseases and old fractures for patients aged 65 years or elderly with VCFs after minimally invasive surgery. The risk assessment scale gained high accuracy.

Keywords: vertebral compression fractures, pulmonary complications, risk factors, elderly patients

\section{Introduction}

Vertebral compression fractures (VCFs) may be defined as either a radiographic or a symptomatic clinical event, it was with a high prevalence in females $(\geq 50$ years). ${ }^{1}$ Patients with VCFs may experience severe and prolonged pain that can markedly affect the quality of life. Percutaneous vertebroplasty (PVP) and percutaneous kyphoplasty (PKP) are minimally invasive methods of treating VCFs. PVP is used to stabilize the fracture through injecting polymethylmethacrylate (PMMA) into the vertebral body. PKP uses a balloon to raise the vertebral body height firstly 
and then inject PMMA. A systematic review suggested that minimally invasive surgery decreased blood loss, operative time, and complication rates in comparison to standard open spine surgery. ${ }^{2}$ PVP and PKP are two preferred surgeries for elderly patients with VCFs, for the benefits of smaller trauma and shorter needed time. ${ }^{3-5}$

Some studies have reported that elderly patients (aged 65 years or elderly) have a significantly increased risk of postoperative infection, of which pulmonary complications are particularly common in clinical treatment. ${ }^{6,7}$ For example, complications of pulmonary embolism (PE), infection and paraplegia would occur after PVP and PKP. ${ }^{8-10}$ More underlying diseases, bigger trauma after spinal surgery and longer operation time are all risk factors for increased incidence of postoperative pulmonary complications. ${ }^{11-13}$ The occurrence of postoperative pulmonary complications significantly increased the in-hospital morbidity and mortality, as well as prolonged hospitalization, increased costs, and compromised quality of life. ${ }^{12,14-17}$ However, the risk factors of pulmonary complications after minimally invasive surgery for elderly patients with VCFs have not been reported and no risk assessment table established.

Lee et al have reported that age and surgical invasiveness were significant risk factors for patients who underwent spine procedures to infect complications during the perioperative period. ${ }^{13}$ Specialists believed that quantitative indicators based on these risk factors can help clinicians to stratify the risk of perioperative complications in patients undergoing spinal surgery. ${ }^{13,17}$ After stratifying the risk factors, measures of prevention and treatment of perioperative complications were determined. All of these results could be used to establish prediction models whereby the probability of a postoperative complication can be predicted for each patient who undergoes spine surgery.

Therefore, in this study, elderly patients (age $\geq 65$ years) with VCFs, who underwent PVP or PKP at Hebei General Hospital from January 2011 to December 2016, were included. It might be the first time to determine risk factors of pulmonary complications after minimally invasive surgery for elderly patients with VCFs by univariate and binary logistic regression analyses. A risk assessment scale for such patients attempted to be established based on the relevant literature and our findings, which may be efficient for doctors and nurses to assess the risk of postoperative pulmonary complications.

\section{Patients and Methods}

\section{Patients}

The research was approved by the ethics committee of Hebei General Hospital (NO. 201821). Written informed consent was obtained from all individual participants. Patients who underwent PVP or PKP at Hebei General Hospital from January 2011 to December 2016 were retrospectively collected and studied. Inclusion criteria of patients were as follows: 1) age $\geq 65$ years; 2) fulfilled the follow-up no less than 1 year after surgery; 3) with VCFs; 4) diagnosed by PVP or PKP surgery. The exclusion criteria of patients were as follows: 1) with severe pulmonary disease before operation; 2) were diagnosed with combining fractures in other parts; 3 ) had incomplete data; 4) age $<65$ years.

\section{Diagnostic of VCFs and Pulmonary Complication}

VCFs were diagnosed by imaging tests such as X-ray or computed tomography (CT) scan. According to the imaging test, vertebral morphology changes, such as flattening, wedge change and pedicle damage, were defined as VCFs. Fractures within 3 weeks were considered as fresh fractures, and fractures older than 3 weeks were considered to be old fractures. The time of fracture was judged by the patients' self-reported injury and the earliest diagnosis imaging of VCFs.

In the present study, fever, pulmonary inflammation, upper respiratory tract infection, venous thrombosis of lower extremity, urinary infection, pleural effusion, arrhythmia and gastrointestinal discomfort were all the complications after operation. Pulmonary complication was diagnosed by patients' symptoms of pulmonary inflammation, upper respiratory tract infection, pulmonary embolism and pleural effusion.

\section{PVP or PKP Surgery}

PVP and PKP are the preferred treatment for elderly patients with VCFs. PVP is a process of injecting bone cement into the fractured vertebra under local anesthesia, which is performed under the guidance of fluoroscopy. A disposable bone biopsy needle or trocar is inserted into the vertebral body for operation through the safe path under imaging guiding. ${ }^{18,19}$ PVP is mainly used for VCFs with a small degree of fracture compression, not significant loss of vertebral height and inconspicuous kyphosis. PKP uses an expandable bone filler to restore 
Table I Univariate Analysis of Related Factors Between Patients with and Without Pulmonary Complications

\begin{tabular}{|c|c|c|c|c|c|}
\hline Risk Factors & $P C(n=27)$ & NPC $(n=206)$ & Odds Ratio & $95 \% \mathrm{Cl}$ & P-value \\
\hline \multicolumn{6}{|l|}{ Gender } \\
\hline Male & 11 & 58 & 1.754 & $0.768-4.005$ & 0.178 \\
\hline Female & 16 & 148 & & & \\
\hline Age & $78.89 \pm 7.65$ & $75.56 \pm 6.62$ & & $0.606-6.046$ & 0.017 \\
\hline BMI & $25.19 \pm 2.84$ & $23.56 \pm 3.05$ & & $0.397-2.84 I$ & 0.01 \\
\hline \multicolumn{6}{|l|}{ Smoking } \\
\hline Yes & 11 & 47 & 2.326 & $1.010-5.354$ & 0.043 \\
\hline No & 16 & 159 & & & \\
\hline \multicolumn{6}{|l|}{ Alcohol abuse } \\
\hline Yes & 4 & 35 & 0.85 & $0.277-2.610$ & 0.992 \\
\hline No & 23 & $|7|$ & & & \\
\hline \multicolumn{6}{|l|}{ Diabetes } \\
\hline Yes & 6 & 36 & 1.349 & $0.508-3.580$ & 0.736 \\
\hline No & 21 & 170 & & & \\
\hline \multicolumn{6}{|l|}{ Cardiovascular diseases } \\
\hline Yes & 19 & 99 & 2.567 & $1.075-6.128$ & 0.029 \\
\hline No & 8 & 107 & & & \\
\hline \multicolumn{6}{|l|}{ Prior spine surgery } \\
\hline Yes & 5 & 58 & 0.58 & $0.210-1.604$ & 0.289 \\
\hline No & 22 & 148 & & & \\
\hline \multicolumn{6}{|l|}{ Surgical procedure } \\
\hline PKP & 9 & 47 & 1.691 & $0.713-4.012$ & 0.229 \\
\hline PVP & 18 & 159 & & & \\
\hline \multicolumn{6}{|l|}{ Surgical site } \\
\hline Thoracic & II & 86 & & & 0.78 \\
\hline Lumbar & 13 & 105 & & & \\
\hline Thoracic + Lumbar & 3 & 15 & & & \\
\hline \multicolumn{6}{|l|}{ Lumbar Lumbar Lumbar } \\
\hline \multicolumn{6}{|l|}{ Surgical levels } \\
\hline 1 & 22 & $|5|$ & 1.603 & $0.579-4.440$ & 0.361 \\
\hline$\geq 2$ & 5 & 55 & & & \\
\hline \multicolumn{6}{|l|}{ Older fractures } \\
\hline Yes & 7 & 20 & 3.255 & $1.226-8.643$ & 0.031 \\
\hline No & 20 & 186 & & & \\
\hline Preoperative LOS & $2.85 \pm 3.49$ & $1.92 \pm 1.72$ & & $-0.470-2.329$ & 0.185 \\
\hline Total LOS & $5.59 \pm 4.72$ & $5.79 \pm 6.49$ & & $-2.74 \mid-2.354$ & 0.881 \\
\hline \multicolumn{6}{|l|}{ Grade of VSA } \\
\hline$\leq 5$ & 22 & 158 & 1.337 & $0.480-3.711$ & 0.577 \\
\hline$>5$ & 5 & 48 & & & \\
\hline
\end{tabular}

Abbreviations: PC, pulmonary complications; NPC, no pulmonary complications; $\mathrm{Cl}$, confidence intervals; BMI, body mass index; PKP, percutaneous kyphoplasty; PVP, percutaneous vertebroplasty; LOS, length of stay; VSA, visual analogue score.

the vertebral body and reach to its original height, as well as create a cavity to be filled with bone cement. ${ }^{18,19}$ PKP is mainly used for VCFs with significant loss of vertebral height and obvious kyphosis. PVP and PKP have no absolute differences in surgical indications. In addition, patients' income will also affect the choice of surgical 
Table 2 Unconditional Binary Logistic Regression Analysis of Risk Factors for Pulmonary Complications

\begin{tabular}{|l|l|l|l|l|l|l|}
\hline Risk Factors & $\boldsymbol{\beta}$ & $\mathbf{O R}$ & $\mathbf{9 5 \%} \mathbf{~ C l}$ & Standardized Error & Wald $\chi^{\mathbf{2}}$ & P-value \\
\hline BMI & 1.032 & 2.807 & $1.14-6.94$ & 0.462 & 4.999 & 0.025 \\
Cardiovascular diseases & 1.622 & 5.065 & $1.72-14.88$ & 0.550 & 8.710 & 0.003 \\
Older fractures & 1.214 & 3.368 & $1.45-7.83$ & 0.431 & 7.951 & 0.005 \\
\hline
\end{tabular}

Abbreviations: $\mathrm{Cl}$, confidence intervals; $\mathrm{BMI}$, body mass index.

methods, because PKP is more expensive than PVP surgery.

\section{Risk Factors}

Gender, age, body mass index (BMI), smoking, alcohol abuse, diabetes, cardiovascular diseases, prior spine surgery, surgical procedure, surgical site, surgical levels, old fractures, preoperative hospitalization days, hospitalization days and grade of visual analogue score (VSA) were used to analyze the risk factors of pulmonary complications after minimally invasive surgery for elderly patients with VCFs. The duration of old fractures are defined as $\geq 3$ weeks.

\section{Establishment of the Risk Assessment Scale}

A risk assessment scale about elderly patients (age $\geq 65$ years) with VCFs after treating by PVP or PKP surgery was established based on physiological and surgical scores for mortality and morbidity as well as our finding ${ }^{14}$ (Table 3). Assessment indicators included age, BMI,

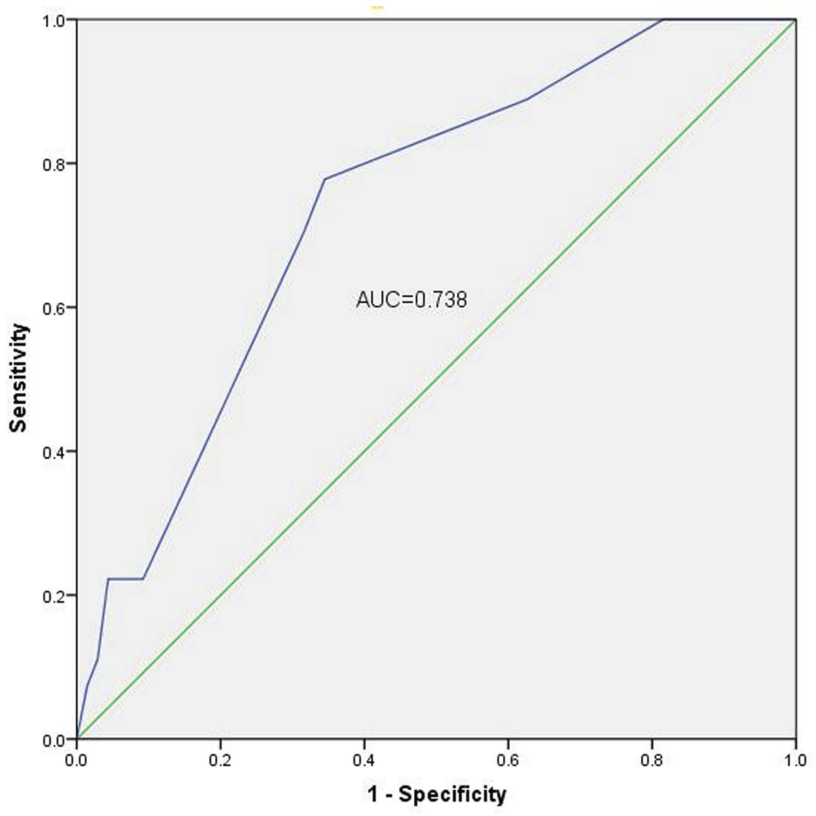

Figure I Area under the curve of the predicted meaningful and risk factors. smoking duration, the number of combined diseases, duration of VCFs, bed rest duration. The highest score was 19 of all these indicators (Table 3). Preoperative hospitalization days, type of anesthesia, duration of operation would also be involved in postoperative evaluation. Each index owned scores which are separated by three levels, 1 point, 2 point and 3 point, respectively. The highest total score is 28 points (Table 3). A total of 53 elderly patients with VCFs were enrolled in the study to test the accuracy of the risk assessment scale. Inclusion criteria: 1) age $\geq 65$ years; 2) patients with VCFs who would be treated with PVP or PKP; 3) in general good condition; 4) patients without bedridden. Exclusion criteria: 1) patients with severe pulmonary disease before operation; 2) combining with fractures other than the spine; 3) requiring other operations.

\section{Statistical Analysis}

Statistical analysis was performed using SPSS 21.0 (IBM). Continuous variables were expressed as means \pm standard deviation and analyzed by independent samples $T$ test. $\chi^{2}$ test was used for categorical and discrete variables. Risk factors were searched by unconditional binary logistic regression, which were independent variables with univariate analysis of $\mathrm{P}<0.05$, and the dependent variables were with or without pulmonary complication. The ROC curve was used to evaluate the effect of the logistic regression model. P value of less than 0.05 was considered significant.

\section{Results}

A total of 249 patients were enrolled in this study. However, among them, 13 patients with severe pulmonary disease before operation and 3 patients without following up were excluded. Finally, a total of 233 patients were included in this retrospective study, among which 27 patients $(11.59 \%)$ had pulmonary complications after surgery including pleural effusion in 7 patients and pulmonary infection in 20 patients. These 27 patients were 78.89 \pm 7.65 years old and included 11 females and 16 males. The remaining 206 patients $(88.41 \%)$ without pulmonary 
Table 3 Risk Assessment Scale of Pulmonary Complications After Minimally Invasive Surgery for Elderly Patients with VCFs

\begin{tabular}{|c|c|c|c|c|c|}
\hline \multirow[t]{2}{*}{ Stage } & \multirow[t]{2}{*}{ Items } & \multicolumn{3}{|c|}{ Grading Rules and Scores } & \multirow[t]{2}{*}{ Score } \\
\hline & & I & 2 & 3 & \\
\hline \multirow[t]{8}{*}{ Preoperative assessment } & I. Age (years) & $65-74$ & $75-84$ & $\geq 85$ & \\
\hline & 2. BMI & $18-23$ & $24-29$ & $\geq 30,<18$ & \\
\hline & 3. Smoking duration (years) & $<10$ & $11-20$ & $\geq 21$ & \\
\hline & 4.I Combined diseases (number) & I & 2 & $\geq 3$ & \\
\hline & 4.2 Chronic pulmonary diseases & Yes & & & \\
\hline & 5. Duration of VCFs (days) & $\leq 7$ & $8-20$ & $\geq 21$ & \\
\hline & 6. Bed rest duration (days) & $\leq 7$ & $8-20$ & $\geq 21$ & \\
\hline & \multicolumn{4}{|l|}{ Preoperative assessment scores } & \\
\hline \multirow[t]{3}{*}{ Postoperative assessment } & 7. Preoperative LOS & 1 & 2 & $\geq 3$ & \\
\hline & 8. Type of anesthesia & Local & Spinal & General & \\
\hline & 9. Duration of operation (minutes) & $>30$ & $>60$ & $>90$ & \\
\hline \multicolumn{5}{|l|}{ Total scores } & \\
\hline
\end{tabular}

Abbreviations: BMI, body mass index; Combined diseases, diabetes mellitus, chronic cardiovascular and cerebrovascular diseases; LOS, length of stay.

complications were $75.56 \pm 6.62$ years and included 148 females and 58 males. There were statistically significant differences between patients with and without pulmonary complications in terms of age, BMI, smoking, cardiovascular diseases, old fractures $(\mathrm{P}<0.05$, Table 1$)$.

Meaningful factors (age, BMI, smoking, cardiovascular diseases, old fractures) and risk factors (smoking and age) considered by clinical experts were added to unconditional binary logistic regression analysis. Logistic regression analysis showed that BMI, cardiovascular diseases and old fractures were risk factors of pulmonary complications after PVP or PKP surgery for elderly patients with VCFs. $(\mathrm{P}<0.05$, Table 2). Area under the receiver operating characteristic curve (AUC) can be used to measure the reliability of the model, with values close to 1.0 indicating high diagnostic accuracy. ${ }^{13,20}$ AUC was 0.738 (95\% CI: $0.648-0.828$, Figure 1), which meant the above indicators were reliability.

Based on Physiological and Operative Severity Score for the Enumeration of Mortality and Morbidity (POSSUM) ${ }^{13,21}$ a risk assessment table was established for patients in this study (Table 3). There were 9 evaluation indicators including preoperative and postoperative evaluation indicators. Age, BMI, smoking duration, number of combined diseases, duration of vertebral compression fractures and bed rest duration were preoperative evaluation indicators. The postoperative evaluation indicators include preoperative hospitalization days, type of anesthesia and duration of operation were postoperative evaluation indicators. Each index scored 1, 2 and 3 points, respectively. The highest total score was 28 (Table 3 ). 53 elderly patients with VCFs were assessed from January to June 2017, among them 5 patients occurred pulmonary complications after PVP or PKP ( 3 patients with pleural effusion and 2 patients with pulmonary infection) (Table 4). The 5 patients with pulmonary complications aged from 72 to 94 years (average 84.6 years) and included 3 males and 2 females. The 48 patients without pulmonary complications aged from 65 to 90 years (average 74.3 years) and included 9 males and 39 females. The ages ranged from 90 to 65 , with an average age of 74.3 . Risk assessment table was used to assess the specific values (Table 4). All the above data were analyzed by ROC curve and the area under the curve could evaluate the accuracy of the assessment. Area under the curve of preoperative and total risk assessment values were all 0.925 , which revealed the evaluation with high accuracy (Figures 2 and 3). Risk assessment values suggested that patients with preoperative assessment scores more than 10.5 or total of over 14.5 had a high risk of complications (Tables 5 and 6).

\section{Discussion}

The World Health Organization (WHO) has found that VCFs are the most common type of osteoporotic fractures, which mainly affect the elderly. In recent years, about 20 million patients are prone to affecting osteoporotic VCFs. ${ }^{22}$ VCFs would cause severe pain, confine spin activity and decrease quality of life. Treatments for VCFs include both nonsurgical and surgical treatment. 
Table 4 Scores of 53 Patients Assessed by Assessment Table

\begin{tabular}{|c|c|c|c|}
\hline Variable & Assignment & $\begin{array}{l}\text { PC } \\
\text { (5 Cases) }\end{array}$ & $\begin{array}{l}\text { NPC } \\
\text { (48 Cases) }\end{array}$ \\
\hline Gender & $\begin{array}{l}\text { Male } \\
\text { Female }\end{array}$ & $\begin{array}{l}3 \\
2\end{array}$ & $\begin{array}{l}9 \\
39\end{array}$ \\
\hline Age (years) & $\begin{array}{l}65-74 \\
75-84 \\
\geq 85\end{array}$ & $\begin{array}{l}1 \\
2 \\
2\end{array}$ & $\begin{array}{l}28 \\
14 \\
6\end{array}$ \\
\hline BMI & $\begin{array}{l}18-23 \\
24-29 \\
\geq 30,<18\end{array}$ & $\begin{array}{l}1 \\
4 \\
0\end{array}$ & $\begin{array}{l}12 \\
34 \\
2\end{array}$ \\
\hline Smoking duration (years) & $\begin{array}{l}\text { No smoking } \\
<10 \\
10-20 \\
\geq 21\end{array}$ & $\begin{array}{l}2 \\
0 \\
3 \\
0\end{array}$ & $\begin{array}{l}36 \\
6 \\
1 \\
5\end{array}$ \\
\hline $\begin{array}{l}\text { Combined diseases } \\
\text { (number) }\end{array}$ & $\begin{array}{l}1 \\
2 \\
3 \\
\geq 3\end{array}$ & $\begin{array}{l}0 \\
2 \\
0 \\
3\end{array}$ & $\begin{array}{l}12 \\
12 \\
6 \\
7\end{array}$ \\
\hline $\begin{array}{l}\text { Chronic pulmonary } \\
\text { diseases }\end{array}$ & Yes & 3 & 2 \\
\hline $\begin{array}{l}\text { Duration of VCFs } \\
\text { (days) }\end{array}$ & $\begin{array}{l}\leq 7 \text { days } \\
7-20 \\
\geq 21\end{array}$ & $\begin{array}{l}1 \\
1 \\
3\end{array}$ & $\begin{array}{l}20 \\
17 \\
11\end{array}$ \\
\hline Bed rest duration (days) & $\begin{array}{l}\leq 7 \text { days } \\
7-20 \\
\geq 21\end{array}$ & $\begin{array}{l}3 \\
0 \\
2\end{array}$ & $\begin{array}{l}41 \\
7 \\
0\end{array}$ \\
\hline Preoperative LOS & $\begin{array}{l}1 \\
2 \\
\geq 3\end{array}$ & $\begin{array}{l}2 \\
0 \\
3\end{array}$ & $\begin{array}{l}25 \\
10 \\
13\end{array}$ \\
\hline Type of anesthesia & $\begin{array}{l}\text { Local } \\
\text { anesthesia } \\
\text { Spinal } \\
\text { anesthesia } \\
\text { General } \\
\text { anesthesia }\end{array}$ & $\begin{array}{l}5 \\
0 \\
0\end{array}$ & $\begin{array}{l}48 \\
0 \\
0\end{array}$ \\
\hline $\begin{array}{l}\text { Duration of operation } \\
\text { (minutes) }\end{array}$ & $\begin{array}{l}>30 \text { mins } \\
>60 \text { mins } \\
>90 \text { mins }\end{array}$ & $\begin{array}{l}3 \\
2 \\
0\end{array}$ & $\begin{array}{l}39 \\
9 \\
0\end{array}$ \\
\hline
\end{tabular}

Abbreviations: Combined diseases, diabetes mellitus, chronic cardiovascular and cerebrovascular diseases; VCFs, vertebral compression fractures; LOS, length of stay; PC, pulmonary complications; NPC, no pulmonary complications.

Nonsurgical treatment includes the administration of antiosteoporotic drugs, pain control, bed rest, support and physical therapy. ${ }^{1}$ However, more than $30 \%$ of patients are compelled to be hospitalized due to ineffective nonsurgical treatment. ${ }^{23,24}$ In addition, traditional spinal

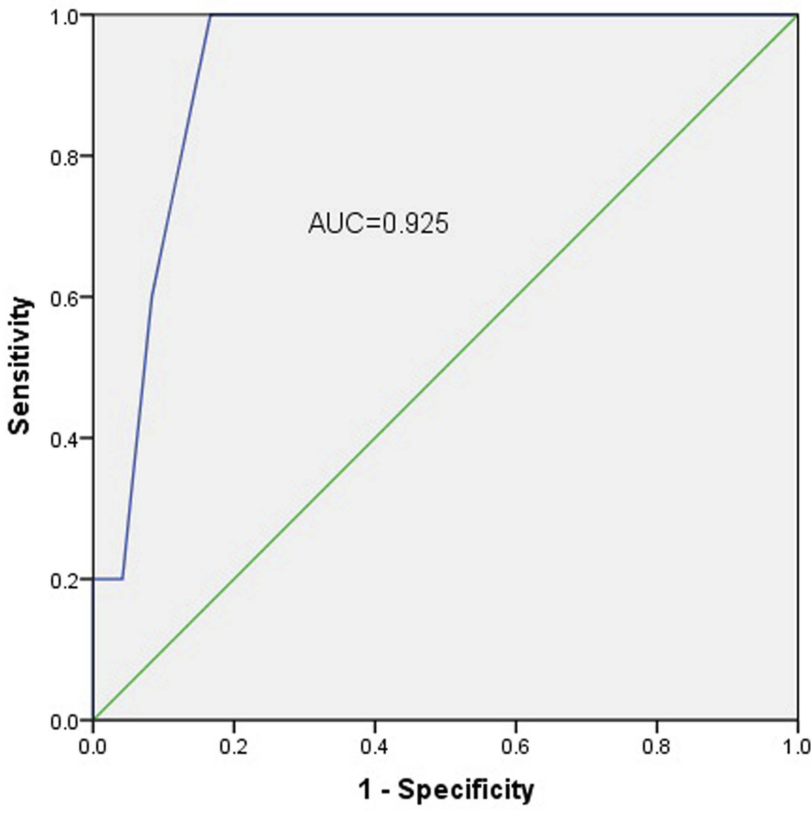

Diagonal segments are produced by ties.

Figure 2 Area under the curve of preoperative risk assessment values.

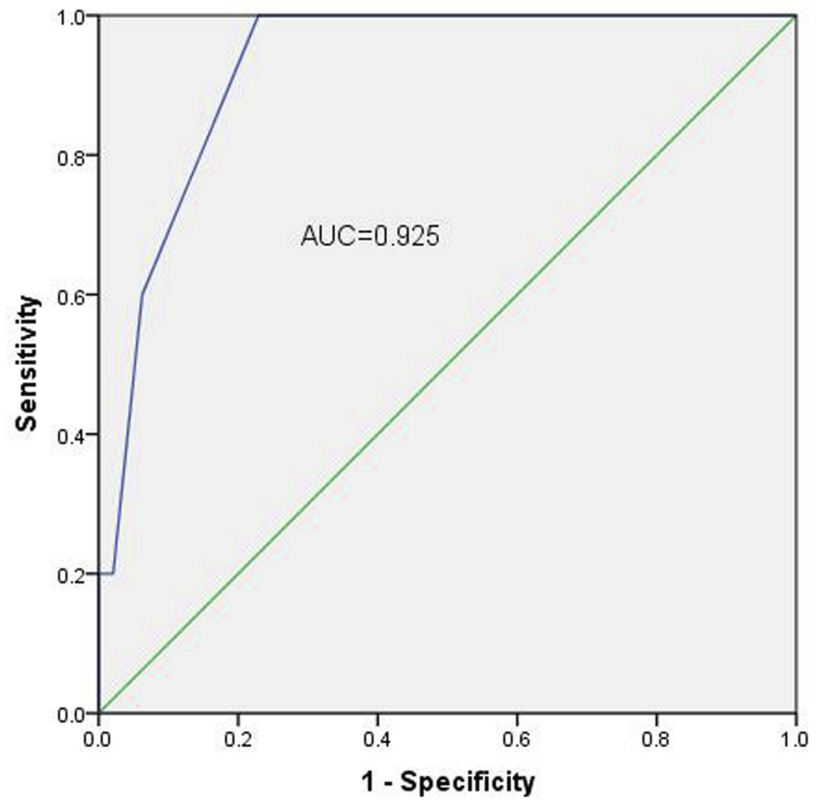

Diagonal segments are produced by ties.

Figure 3 Area under the curve of total risk assessment values.

surgery has been abandoned due to the large trauma site and potentially high incidence of complications. ${ }^{25}$

Minimally invasive surgery, such as PVP and PKP, could be served as the preferred treatment for elderly patients with VCFs, which can effectively stabilize the 
Table 5 Test Result Variable(S): Preoperative Risk Assessment Values

\begin{tabular}{|l|l|l|}
\hline $\begin{array}{l}\text { Positive If Greater Than or } \\
\text { Equal To }\end{array}$ & Sensitivity & I - Specificity \\
\hline 3.00 & 1.000 & 1.000 \\
4.50 & 1.000 & 0.979 \\
5.50 & 1.000 & 0.917 \\
6.50 & 1.000 & 0.667 \\
7.50 & 1.000 & 0.479 \\
8.50 & 1.000 & 0.396 \\
9.50 & 1.000 & 0.250 \\
10.50 & 1.000 & 0.167 \\
11.50 & 0.600 & 0.083 \\
12.50 & 0.200 & 0.042 \\
14.00 & 0.200 & 0.000 \\
16.00 & 0.000 & 0.000 \\
\hline
\end{tabular}

Notes: The test result variable(s): Preoperative has at least one tie between the positive and negative actual state groups. ${ }^{2}$ The smallest cutoff value is the minimum observed test value minus I, and the largest cutoff value is the maximum observed test value plus I. All the other cutoff values are the averages of two consecutive ordered observed test values.

Table 6 Test Result Variable(S): Total Risk Assessment Values

\begin{tabular}{|l|l|l|}
\hline $\begin{array}{l}\text { Positive If Greater Than or } \\
\text { Equal To }\end{array}$ & Sensitivity & I - Specificity \\
\hline 6.00 & 1.000 & 1.000 \\
7.50 & 1.000 & 0.979 \\
8.50 & 1.000 & 0.938 \\
9.50 & 1.000 & 0.750 \\
10.50 & 1.000 & 0.625 \\
11.50 & 1.000 & 0.479 \\
12.50 & 1.000 & 0.396 \\
13.50 & 1.000 & 0.292 \\
14.50 & 1.000 & 0.229 \\
15.50 & 0.800 & 0.146 \\
16.50 & 0.600 & 0.063 \\
17.50 & 0.200 & 0.021 \\
18.50 & 0.200 & 0.000 \\
20.00 & 0.000 & 0.000 \\
\hline
\end{tabular}

Notes: The test result variable(s): Total has at least one tie between the positive and negative actual state groups. ${ }^{\text {aT }}$ The smallest cutoff value is the minimum observed test value minus I, and the largest cutoff value is the maximum observed test value plus I. All the other cutoff values are the averages of two consecutive ordered observed test values.

spine, relieve pain and significantly improve the quality of life. $^{2,25-27}$ However, complications such as pulmonary complications after minimally invasive surgery could lead to a straight decline in the survival rate of elderly patients with VCFs. ${ }^{8-10}$ Obesity, as a risk factor for pulmonary complications after spinal surgery, was also revealed to be a risk factor of $\mathrm{PE}$ after spinal surgery. ${ }^{6,28-31}$ Besides, hypertension and cardiovascular diseases were also identified as the risk factors of complication after spinal surgery. ${ }^{8,32-35}$ In the present study, we retrospectively evaluated elderly patients ( $\geq 65$ years) diagnosed with VCFs who underwent PVP or PKP surgery. The incidence of pulmonary complications after surgery reached $11.59 \%$ in 233 enrolled patients. Age, BMI, smoking, cardiovascular diseases and old fractures were significantly different between patients with and without pulmonary complications. Logistic regression analysis showed that elderly average age, higher average BMI, old fractures, smoke, or have cardiovascular diseases were risk factors for elderly patients with VCFs.

Patients with VCFs would suffer different degrees of back pain. Pain caused by fractures could limit the patients' physical activities, and subsequently affect the respiratory movement of their lungs. ${ }^{36}$ When the fracture time is more than 3 weeks, delayed union or nonunion of fractures and even necrosis of vertebral body may occur. Patients with VCFs, especially elderly patients, are more likely to develop pulmonary infection if they stay in bed, as well as further increasing pulmonary complications after surgery. Therefore, the established risk assessment table in our study was necessary to prospectively evaluate the risk of pulmonary complications in elderly patients with VCFs. Moreover, the risk assessment table obtained a desirable accuracy (AUC = 0.925 ) and risk assessment values suggested that patients with preoperative assessment scores more than 10.5 or total above 14.5 had a higher risk of pulmonary complications.

This study has several limitations. Firstly, the data were retrospectively collected in a single center which might lead to an unavoidable selection bias. Secondly, some other potential risk factors, such as operative duration, technical level of the operator, the type of compression fractures and so on, were not taken into consideration due to incomplete medical records. Furthermore, the sample sizes in this study are relatively small, and further study with a larger number of samples is warranted. These limitations notwithstanding, the risk factors of pulmonary complications after minimally invasive surgery for elderly patients with VCFs were determined for the first time in our study. Furthermore, the risk assessment table could assess the risk of postoperative pulmonary complications.

In conclusion, targeted prevention interventions should be used to prevent pulmonary complications after minimally invasive surgery for elderly patients with VCFs, in order to comprehensively manage risk factors in the perioperative period. In our research, BMI, cardiovascular diseases and old fractures were defined as significant risk 
factors of pulmonary complications. The established risk assessment scale could help prospectively evaluated risk factors of pulmonary complications after minimally invasive surgery for elderly patients with VCFs.

\section{Abbreviations}

VCFs, vertebral compression fractures; PVP, percutaneous vertebroplasty; PKP, percutaneous kyphoplasty; ROC, receiver operating characteristic; BMI, body mass index; PMMA, polymethylmethacrylate; PE, pulmonary embolism; VSA, visual analogue score; AUC, area under the receiver operating characteristic curve; POSSUM, Physiological and Operative Severity Score for the Enumeration of Mortality and Morbidity; DM, diabetes mellitus; CI, confidence intervals.

\section{Declarations}

This study has been approved by the Ethics Committee of Hebei General Hospital.

\section{Consent for Publication}

Signed informed consents were obtained from parents.

\section{Disclosure}

The authors declare that they have no conflict of interests.

\section{References}

1. Kim DH, Vaccaro AR. Osteoporotic compression fractures of the spine; current options and considerations for treatment. Spine J. 2006;6(5):479-487. doi:10.1016/j.spinee.2006.04.013

2. Molina CA, GZ L, SD M. A systematic review of the current role of minimally invasive spine surgery in the management of metastatic spine disease. Int J Surg Oncol. 2011;2011(2090-1402):598148.

3. Ren H, Shen Y, Zhang Y-Z, et al. Correlative factor analysis on the complications resulting from cement leakage after percutaneous kyphoplasty in the treatment of osteoporotic vertebral compression fracture. J Spinal Disord Tech. 2010;23(7):e9. doi:10.1097/ BSD.0b013e3181c0cc94

4. Fribourg D, Tang C, Sra P, Delamarter R, Bae H. Incidence of subsequent vertebral fracture after kyphoplasty. Spine. 2004;29 (20):2270-2276. doi:10.1097/01.brs.0000142469.41565.2a

5. Lavelle WF, Cheney R. Recurrent fracture after vertebral kyphoplasty. Spine J. 2006;6(5):488-493. doi:10.1016/j.spinee.2005.10.013

6. Schoenfeld AJ, Carey PA, Iii AWC, Bader JO, Bono CM. Patient factors, comorbidities, and surgical characteristics that increase mortality and complication risk after spinal arthrodesis: a prognostic study based on 5887 patients. Spine J. 2013;13(10):1171-1179. doi:10.1016/ j.spinee.2013.02.071

7. Memtsoudis SG, Vougioukas VI, Yan M, Gaber-Baylis LK, Girardi FP. Perioperative morbidity and mortality after anterior, posterior, and anterior/posterior spine fusion surgery. Spine. 2011;36 (22):1867-1877. doi:10.1097/BRS.0b013e3181c7decc

8. Hsueh-Lin C, Chih-Shung W, Shung-Tai H, Fang-Lin C, Che-Hao H, Ching-Tang W. A lethal pulmonary embolism during percutaneous vertebroplasty. Anesth Analg. 2002;95(4):1060-1062.
9. Olmos MA, González AS, Clemente JD, Tomé CV. Infected vertebroplasty due to uncommon bacteria solved surgically: a rare and threatening life complication of a common procedure. Spine. 2006;31(20):770-773. doi:10.1097/01.brs.0000240202.91336.99

10. Lee BJ, Lee SR, Yoo TY. Paraplegia as a complication of percutaneous vertebroplasty with polymethylmethacrylate: a case report. Spine. 2002;27(19):419-422. doi:10.1097/00007632-200210010-00022

11. Cotton BA, Pryor JP, Chinwalla I, Wiebe DJ, Reilly PM, Schwab CW. Respiratory complications and mortality risk associated with thoracic spine injury. J Trauma-Injury Infect Crit Care. 2005;59 (6):1400. doi:10.1097/01.ta.0000196005.49422.e6

12. Masuda K, Chikuda H, Yasunaga H, et al. Factors affecting the occurrence of pulmonary embolism after spinal surgery: data from the national administrative database in Japan. Spine J. 2012;12 (11):1029-1034. doi:10.1016/j.spinee.2012.10.020

13. Lee MJ, Konodi MA, Cizik AM, Bransford RJ, Bellabarba C, Chapman JR. Risk factors for medical complication after spine surgery: a multivariate analysis of 1591 patients. Spine. 2012;12 (3):197-206. doi:10.1016/j.spinee.2011.11.008

14. Guyot JP, Cizik A, Bransford R, Bellabarba C, Lee MJ. Risk factors for cardiac complications after spine surgery. Evid Based Spine Care J. 2010;1(02):26-33. doi:10.1055/s-0028-1100910

15. Bohl DD, Mayo BC, Massel DH, et al. Incidence and risk factors for pneumonia following posterior lumbar fusion procedures: an ACS-NSQIP study. Spine. 2016;41(12):1058-1063. doi:10.1097/ BRS.0000000000001389

16. Bohl DD, Ahn J, Rossi VJ, Tabaraee E, Grauer JN, Singh K. Incidence and risk factors for pneumonia following anterior cervical decompression and fusion procedures: an ACS-NSQIP study. Spine J. 2016;16(3):335-342. doi:10.1016/j.spinee.2015.11.021

17. Fineberg SJ, Matthew O, Patel AA, Kern S. Incidence, risk factors, and mortality associated with aspiration in cervical spine surgery. Spine. 2013;38(19):1189-1195. doi:10.1097/BRS.0b013e31829cc19b

18. Phillips FM, Erling H, Marion CH, Thomas MN, Wetzel F, Todd PG. Early radiographic and clinical results of balloon kyphoplasty for the treatment of osteoporotic vertebral compression fractures. Spine. 2003;28(19):2265-2267. doi:10.1097/01.BRS.0000085092.84097.7B

19. Ledlie JT, Renfro M. Balloon kyphoplasty: one-year outcomes in vertebral body height restoration, chronic pain, and activity levels. J Neurosurg. 2003;98(1):36-42. doi:10.3171/spi.2003.98.1.0036

20. Rosner B, Tworoger S, Qiu W. Correcting AUC for measurement error. J Biom Biostat. 2015;6:5. doi:10.4172/2155-6180.1000270

21. Imposti F, Cizik A, Bransford R, Bellabarba C, Lee MJ. Risk factors for pulmonary complications after spine surgery. Evid Based Spine Care J. 2010;1(2):26-33. doi:10.1055/s-0028-1100911

22. Hasegawa K, Homma T, Uchiyama S, Takahashi HE. Osteosynthesis without instrumentation for vertebral pseudarthrosis in the osteoporotic spine. J Bone Joint Surg Br Vol. 1997;79(3):452. doi:10.1302/ 0301-620X.79B3.0790452

23. Melton LJ 3rd, Kan SH, Frye MA, Wahner HW, O'Fallon WM, Riggs BL. Epidemiology of vertebral fractures in women. $\mathrm{Am}$ J Epidemiol. 1989;129(5):1000-1011. doi:10.1093/oxfordjournals. aje.a115204

24. Wasnich RD. Vertebral fracture epidemiology. Bone. 1996;18(3 Suppl):179S-183S. doi:10.1016/8756-3282(95)00499-8

25. Tang H, Zhao J, Hao C. Osteoporotic vertebral compression fractures: surgery versus non-operative management. J Funct Mater. 2007;39(4):1438.

26. Pasquale DN, Tiziana T, Gianluca P, Pasqualina M. Treatment of painful osteoporotic or traumatic vertebral compression fractures by percutaneous vertebral augmentation procedures: a nonrandomized comparison between vertebroplasty and kyphoplasty. Clin J Pain. 2007;23(5):425-430. doi:10.1097/AJP.0b013e31805593be

27. Brian JG, Mark K, PC C, Yan Z, Robert S. Comparing pain reduction following kyphoplasty and vertebroplasty for osteoporotic vertebral compression fractures. Chin J Osteoporosis. 2009;10(4):583-590. 
28. Kalanithi PA, Arrigo R, Boakye M. Morbid obesity increases cost and complication rates in spinal arthrodesis. Spine. 2012;37 (11):982-988. doi:10.1097/BRS.0b013e31823bbeef

29. Yang R, Wu Y, Yao L, et al. Risk factors of postoperative pulmonary complications after minimally invasive anatomic resection for lung cancer. Ther Clin Risk Manag. 2019;15:223-231. doi:10.2147/ TCRM.S195010

30. Mancuso P. Obesity and lung inflammation. J Appl Physiol. 2010;108 (3):722-728. doi:10.1152/japplphysiol.00781.2009

31. De L, Goodwin CR, Abu-Bonsrah N, et al. Patient and operative factors associated with complications following adolescent idiopathic scoliosis surgery: an analysis of 36,335 patients from the nationwide inpatient sample. J Neurosurg Pediatr. 2016;25(6):1-7.

32. Lee MJ, Konodi MA, Cizik AM, et al. Risk factors for medical complication after cervical spine surgery: a multivariate analysis of 582 patients. Spine. 2012;12(3):197-206. doi:10.1016/j.spinee.2011.11.008
33. Ufoaroh CU, Ele PU, Anyabolu AE, et al. Pre-operative pulmonary assessment and risk factors for post-operative pulmonary complications in elective abdominal surgery in Nigeria. Afr Health Sci. 2019;19(1):1745-1756. doi:10.4314/ahs.v19i1.51

34. Agostini PJ, Lugg ST, Adams K, et al. Risk factors and short-term outcomes of postoperative pulmonary complications after VATS lobectomy. J Cardiothorac Surg. 2018;13(1):28. doi:10.1186/ s13019-018-0717-6

35. Strøm C, Rasmussen LS, Steinmetz J. Practical management of anaesthesia in the elderly. Drugs Aging. 2016;33(11):765-777. doi:10.1007/s40266-016-0413-y

36. Gangi A, Sabharwal T, Fg BX, Morales J, Adam A. Quality assurance guidelines for percutaneous vertebroplasty. Cardiovasc Intervent Radiol. 2006;29(2):173-178. doi:10.1007/s00270-005-0146-5

\section{Publish your work in this journal}

Therapeutics and Clinical Risk Management is an international, peerreviewed journal of clinical therapeutics and risk management, focusing on concise rapid reporting of clinical studies in all therapeutic areas, outcomes, safety, and programs for the effective, safe, and sustained use of medicines. This journal is indexed on PubMed Central, CAS,
EMBase, Scopus and the Elsevier Bibliographic databases. The manuscript management system is completely online and includes a very quick and fair peer-review system, which is all easy to use. Visit http://www.dovepress.com/testimonials.php to read real quotes from published authors. 